\title{
Using high-frequency water quality data to assess sampling strategies for the EU Water Framework Directive
}

\author{
R. A. Skeffington ${ }^{1}$, S. J. Halliday ${ }^{1}$, A. J. Wade $^{1}$, M. J. Bowes ${ }^{2}$, and M. Loewenthal ${ }^{3}$ \\ ${ }^{1}$ Dept. of Geography and Environmental Sciences, University of Reading, Reading, RG6 6DW, UK \\ ${ }^{2}$ Centre for Ecology and Hydrology, Wallingford, Oxon., OX10 8BB, UK \\ ${ }^{3}$ Environment Agency, Fobney Mead, Reading, RG2 0SF, UK
}

Correspondence to: R. A. Skeffington (r.a.skeffington@ reading.ac.uk)

Received: 17 December 2014 - Published in Hydrol. Earth Syst. Sci. Discuss.: 28 January 2015

Accepted: 8 May 2015 - Published: 26 May 2015

\begin{abstract}
The EU Water Framework Directive (WFD) requires that the ecological and chemical status of water bodies in Europe should be assessed, and action taken where possible to ensure that at least "good" quality is attained in each case by 2015. This paper is concerned with the accuracy and precision with which chemical status in rivers can be measured given certain sampling strategies, and how this can be improved. High-frequency (hourly) chemical data from four rivers in southern England were subsampled to simulate different sampling strategies for four parameters used for WFD classification: dissolved phosphorus, dissolved oxygen, $\mathrm{pH}$ and water temperature. These data sub-sets were then used to calculate the WFD classification for each site. Monthly sampling was less precise than weekly sampling, but the effect on WFD classification depended on the closeness of the range of concentrations to the class boundaries. In some cases, monthly sampling for a year could result in the same water body being assigned to three or four of the WFD classes with $95 \%$ confidence, due to random sampling effects, whereas with weekly sampling this was one or two classes for the same cases. In the most extreme case, the same water body could have been assigned to any of the five WFD quality classes. Weekly sampling considerably reduces the uncertainties compared to monthly sampling. The width of the weekly sampled confidence intervals was about $33 \%$ that of the monthly for $\mathrm{P}$ species and $\mathrm{pH}$, about $50 \%$ for dissolved oxygen, and about $67 \%$ for water temperature. For water temperature, which is assessed as the 98th percentile in the UK, monthly sampling biases the mean downwards by about $1{ }^{\circ} \mathrm{C}$ compared to the true value, due to problems of assessing high percentiles with limited data. Low-frequency measure-
\end{abstract}

ments will generally be unsuitable for assessing standards expressed as high percentiles. Confining sampling to the working week compared to all 7 days made little difference, but a modest improvement in precision could be obtained by sampling at the same time of day within a $3 \mathrm{~h}$ time window, and this is recommended. For parameters with a strong diel variation, such as dissolved oxygen, the value obtained, and thus possibly the WFD classification, can depend markedly on when in the cycle the sample was taken. Specifying this in the sampling regime would be a straightforward way to improve precision, but there needs to be agreement about how best to characterise risk in different types of river. These results suggest that in some cases it will be difficult to assign accurate WFD chemical classes or to detect likely trends using current sampling regimes, even for these largely groundwaterfed rivers. A more critical approach to sampling is needed to ensure that management actions are appropriate and supported by data.

\section{Introduction}

The principal aim of the EU Water Framework Directive (WFD: EU, 2000) is to protect and enhance the status of aquatic ecosystems in the European Union and to prevent their further deterioration. To support this aim, the status of European waters needs to be assessed by a monitoring programme. In relation to surface (fresh) waters, the subject of this paper, the directive states that "The monitoring network shall be designed so as to provide a coherent and comprehensive overview of ecological and chemical status within 
each river basin and shall permit classification of water bodies into five classes..." (EU, 2000, Annex V, Sect. 1.3). These classes are designated, in increasing order of quality, "bad", "poor", "moderate", "good" and "high". One specific aim of the directive is that all waters should be of at least "good" quality by the year 2015, though derogations from this are possible. If waters fail to meet this standard, then action must be taken to remedy the situation. Monitoring of waters and their assignment to quality classes is thus central to the operation of the WFD, though monitoring also has other objectives such as increasing system understanding and designing mitigation options. Because the quality of all waters varies both spatially and temporally, the representativeness of water samples is a crucial issue. There is a large literature on the design of aquatic monitoring programmes, which invariably covers sampling problems. For instance, Hunt and Wilson (1986, Chap. 3) reviewed 386 references on water sampling up to 1986, Dixon and Chiswell (1996) found about 150 up to 1995 , and more recently Strobl and Robillard (2008) and Horowitz (2013) have reviewed the subject further. There is general agreement in these references about the importance of defining specific objectives for monitoring. Here the WFD is reasonably specific, defining objectives for three types of monitoring, namely surveillance monitoring to establish the present status; operational monitoring aimed at those water bodies at risk of non-compliance with objectives, and investigative monitoring for establishing the reasons for non-compliance and the magnitude of accidental pollution episodes (EU, 2000, Annex V, Sect. 1.3). Both the former types have "assessment of change" as a sub-objective. More detailed guidance on sampling objectives is given in various guidance documents (e.g. EU, 2009). These are the result of much discussion in expert committees, work groups, workshops, etc., but the diversity of surface waters in the EU means these can do little more than state the issues which should be taken into consideration, rather than giving specific guidance.

The WFD also recognises that the variability of surface waters causes problems in classifying them and in trend detection. There is a trade-off between the improved precision and accuracy obtained by sampling more frequently and the increased costs incurred. The issue of sampling frequency is extensively discussed in the reviews quoted above. The WFD states "Frequencies shall be chosen so as to achieve an acceptable level of confidence and precision" (EU, 2000 Annex $\mathrm{V}$, Sect. 1.3.4). What is acceptable is left open, but estimates of confidence and precision have to be quoted in the River Basin Management Plans which are therefore open to public scrutiny. The WFD specifies that monitoring for physicochemical determinands should be not less than 3 months, but leaves open the possibility that monitoring frequencies could be greater or smaller depending on expert judgement. The WFD also recognises the need to take seasonal variation into account, but not, apparently, regular variation on shorter timescales such as diurnal variation. This need is, however, well recognised in the wider literature. Hunt and Wilson (1986, p. 52), for instance, state that where cyclic variations are of similar size to random variation, sampling times "should be chosen so that representative sampling of the cycle is achieved".

The present paper uses high-frequency chemical data from four rivers in southern England to assess the accuracy and precision of the WFD classifications applied to them, and to evaluate some strategies for improving accuracy and precision. The data were subsampled to simulate different sampling frequencies, and to simulate a variety of sampling strategies. This approach has previously been used to evaluate the influence of sampling strategy on stream concentrations (e.g. Kronvang and Bruhn, 1996; Bowes et al., 2009) and estimates of pollutant loading in rivers (e.g. Johnes, 2007; Cassidy and Jordan, 2011), but has not as far as we are aware been applied to WFD classifications. The paper also raises questions about the conclusions which can legitimately be drawn from current monitoring programmes.

\section{Methods}

\subsection{Study sites}

The catchments used for this study are shown in Fig. 1, and some relevant hydrological characteristics in Table 1. More detail on each site is given in the papers quoted in this section. All the rivers are affected to some extent by groundwater abstractions and transfers, a common situation in southern England. The effects of these can be clearly seen in Table 1, with reduced specific flows in the Kennet and enhanced flows in The Cut due to water imports.

The upper River Kennet (Fig. 1a) was sampled at Mildenhall, some $2 \mathrm{~km}$ east of Marlborough (Palmer-Felgate et al., 2008). The catchment consists entirely of chalk of Cretaceous age. The river is predominantly groundwater-fed, with a baseflow index of 0.94 (Table 1), hence a damped hydrological response to rainfall. Land use is predominantly arable agriculture with some intensive livestock farming. The town of Marlborough (pop. ca. 8400) is the only significant urban settlement. Above Marlborough sewage treatment works (STW), the Water Framework Directive classification is "good", deteriorating to "moderate" below (see http://maps.environment-agency.gov.uk/).

The River Enborne (Fig. 1b) was sampled near the catchment outlet at Brimpton (Halliday et al., 2014). Cretaceous chalk underlies the catchment and outcrops in the upper reaches, but much of the surface geology consists of impervious Tertiary clays. The Enborne is thus more hydrologically responsive than the Kennet. Land use is a mixture of grassland, arable and woodland. The WFD classification is a mixture of "good" and "moderate", depending on the reach (Fig. 1b). 


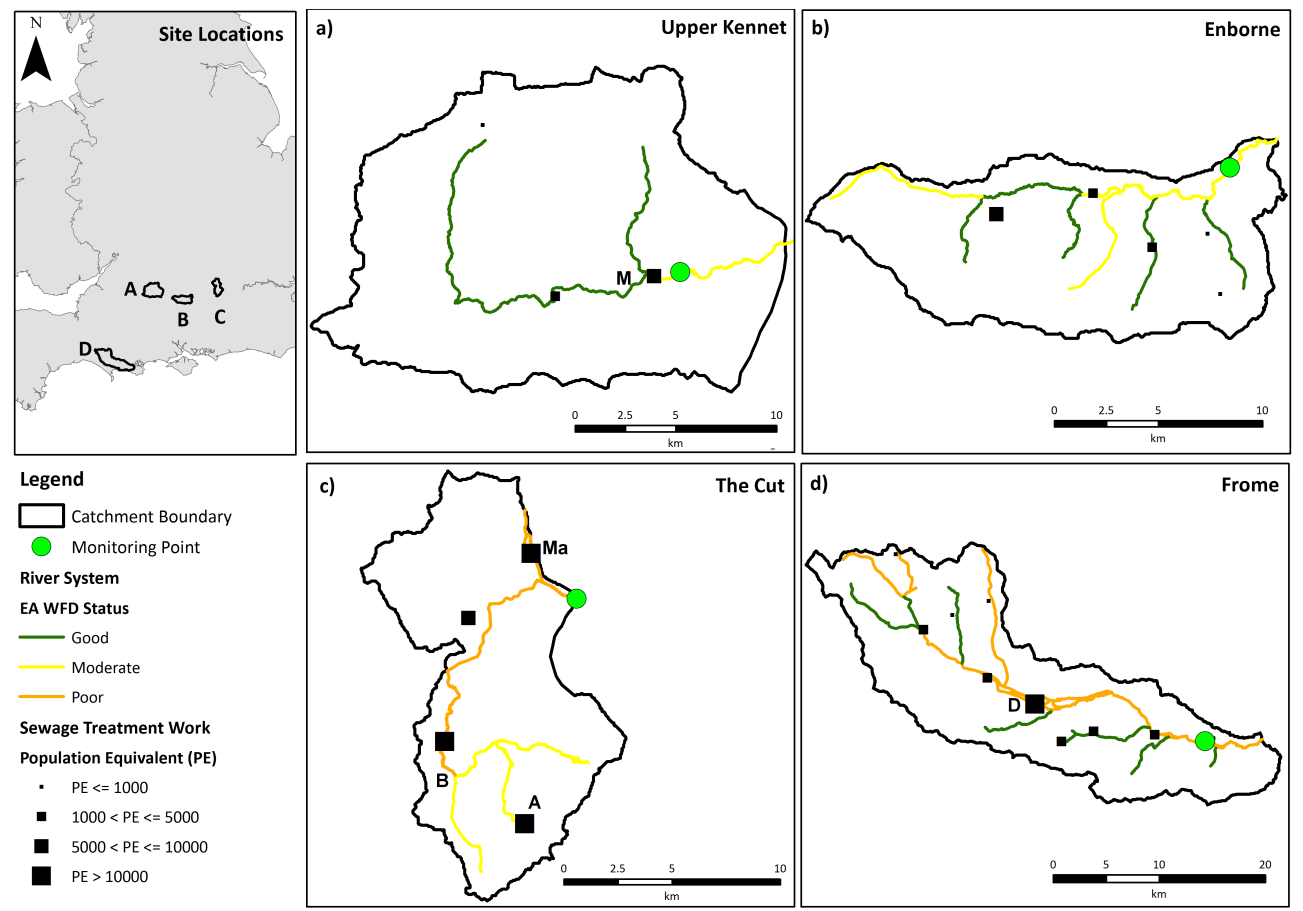

Figure 1. The four river catchments used in this study. The rivers are coloured according to their official status under the EU Water Framework Directive (WFD), as calculated by the English Environment Agency (http://maps.environment-agency.gov.uk/). Larger towns are marked by initials: M, Marlborough; Ma, Maidenhead; B, Bracknell; A, Ascot; D, Dorchester.

Table 1. Some characteristics of the sampled rivers.

\begin{tabular}{lrrrrr}
\hline River & $\begin{array}{r}\text { Catchment } \\
\text { area }\left(\mathrm{km}^{2}\right)\end{array}$ & $\begin{array}{r}\text { Precipitation } \\
\left(\mathrm{mm} \mathrm{yr}^{-1}\right)\end{array}$ & $\begin{array}{r}* \text { Mean } \\
\text { flow }\left(\mathrm{m}^{3} \mathrm{~s}^{-1}\right)\end{array}$ & $\begin{array}{r}\text { Baseflow } \\
\text { index }\end{array}$ & $\begin{array}{r}\text { Population } \\
(2011 \text { census })\end{array}$ \\
\hline Kennet & 220 & 770 & ca. 1.26 & 0.94 & 12800 \\
Enborne & 148 & 790 & 1.31 & 0.53 & 18300 \\
The Cut & 124 & 676 & ca. 1.32 & 0.46 & 190000 \\
Frome & 414 & 968 & 6.65 & 0.84 & 46000 \\
\hline
\end{tabular}

Data from the UK National River flow archive http://www.ceh.ac.uk/data/nrfa/index.html unless otherwise specified. * Only the rivers Enborne and Frome are gauged at the sampling point. Flow in the Kennet was estimated from gauging stations located approximately $2 \mathrm{~km}$ upstream. Flow in The Cut was estimated from a gauging station at Binfield (gauging $50 \mathrm{~km}^{2}$ of the catchment), plus measured discharges from the sewage treatment works, plus an estimate of discharge from the lower part of the catchment based on that from the upper (Halliday et al., 2015).

The Cut (Fig. 1c) was sampled near its confluence with the River Thames at Bray (Wade et al., 2012; Halliday et al., 2015). The catchment geology is predominantly London Clay and Reading Beds (Palaeocene clays and sands), giving an impermeable catchment with a baseflow index of 0.46 . The catchment population is around 190000 , mostly in the large urban centres of Bracknell and Maidenhead. Improved grassland covers $30 \%$ of the catchment and $26 \%$ is classed as arable, mostly in the northern half, and woodland occupies $15 \%$, mostly in the south. River flows are substantially increased by abstraction from the Thames for drinking water (Halliday et al., 2015) and its subsequent release through the STWs, increasing the specific runoff (Table 1). The WFD classification is mostly "poor", being "moderate" only in the upper reaches above the major conurbations. Note the river is called "The Cut"; hence "The" is capitalised throughout.

The River Frome (Fig. 1d) was sampled at East Stoke (Bowes et al., 2005, 2009, 2011). It has been studied for many years as an example of a chalk stream: the geology is mostly chalk, but there are other Cretaceous formations in the headwaters, principally the Gault and Upper Greensand formations in the headwaters, and sands, gravels and clays in the lower catchment. Dorchester (pop. 27 000) is the only significant urban centre. Land use is mainly agricultural, $47 \%$ arable, $39 \%$ grassland and $9 \%$ woodland. There is some aquaculture, mainly watercress growing, affecting the river. The WFD classification is mostly "poor", but "good" in some side streams. 


\subsection{High-frequency water sampling}

Methods for collecting high-frequency water chemistry data varied somewhat between rivers: they are summarised here and are described in more detail in the papers cited below. Sampling of the River Enborne is described in Wade et al. (2012) and Halliday et al. (2014). Sampling began on 1 November 2009 and finished on 29 February 2012. Sampling frequency was hourly. A YSI 6600 multi-parameter sonde was used to measure a standard suite of parameters, including dissolved oxygen, $\mathrm{pH}$ and water temperature. A bankside mains-powered instrument, the Systea Micromac $\mathrm{C}$, was used to make hourly measurements of total reactive phosphorus (TRP). The instrument uses the phosphomolybdenum blue complexation method on an unfiltered sample, hence TRP is an operationally defined measurement, predominantly comprised of orthophosphate $\left(\mathrm{PO}_{4}\right)$ and readily hydrolysable P species.

The River Kennet at Mildenhall was sampled from January 2004 to November 2006 and used the same instrumental set-up as the Enborne, as described by Palmer-Felgate et al. (2008).

The Cut was sampled from April 2010 to February 2012 (Wade et al., 2012; Halliday et al., 2015). Sampling frequency was hourly and measurements of dissolved oxygen, $\mathrm{pH}$ and water temperature were made by a YSI multiparameter sonde as above. Phosphorus species were measured using a Hach Lange Phosphax Sigma which uses phosphomolybdenum blue complexation to measure TRP as above, and also total phosphorus (TP) by acid persulfate digestion after heating to $140^{\circ} \mathrm{C}$, at a pressure of $2.5 \mathrm{bar}$ $(359 \mathrm{kPa})$, followed by phosphomolybdenum blue complexation. There was no filtration step in either analysis.

The River Frome at East Stoke was sampled as described by Bowes et al. (2009) between 1 February 2005 and 31 January 2006, as part of a much longer, lower-frequency study (Bowes et al., 2011). Samples of river water $(500 \mathrm{~mL})$ were taken from approximately the mid depth of the river using an automatic water sampler (Montec Epic, model 1011). Sampling frequency varied from two to four times per day during dry periods and up to eight samples per day during periods of rainfall. A total of 1358 samples were taken over the 1 year monitoring period. Total phosphorus was determined in the laboratory by digesting the sample with acidic potassium persulfate in an autoclave at $121^{\circ} \mathrm{C}$, then reacting with acidic ammonium molybdate reagent to produce phosphomolybdenum blue complex (Murphy and Riley, 1962). Soluble reactive phosphorus (SRP) was determined by filtering river water samples through a $0.45 \mu \mathrm{m}$ cellulose nitrate membrane, and analysing for phosphate as above.

\subsection{Statistical analysis}

As the determination of the WFD status of a water is based on annual means, the data sets were divided into annual sub- sets: 2010 and 2011 for the Enborne; 2004 and 2005 for the Kennet; 2011 for The Cut; and 2005 for the Frome. A standard set of descriptive statistics was then calculated for all the data sets, including those required for WFD determinations in the UK, which are the mean for $\mathrm{P}$ and $\mathrm{pH}$; the 10th percentile for dissolved oxygen; and the 98th percentile for water temperature. The analysis in this paper is restricted to these four variables. Each of the high-frequency annual data sets was then resampled using two different sampling frequencies and five different sampling strategies, to create a series of ten sampling scenarios. Sampling frequency was either monthly or weekly. Within each of these, the strategies were (with abbreviations in brackets) the following:

- sampling at any time (ANY);

- sampling on any day of the week, but restricted to normal working hours, defined as between 09:00 and 17:59 UTC (AW9-18);

- sampling on Monday to Friday only, and also restricted to normal working hours (MF9-18). This is the commonest sampling approach used by the regulatory agencies;

- sample collection on any day, but restricted to a $3 \mathrm{~h}$ window between 09:00 and 11:59 UTC (AW9-12);

- sample collection restricted to Monday to Friday and also restricted to a $3 \mathrm{~h}$ window between 09:00 and 11:59 UTC (MF9-12).

Each of these re-sampling strategies was applied to each data set using the MATLAB function datasample (Mathworks, 2014). This was set up to sample at random from the appropriate hourly time series using a uniform distribution. Only one sample was taken from a given month or week, to replicate a real sampling programme. The data sets were resampled 1000 times, each generating a secondary data set which represents a set of samples which might have been collected if the given sampling strategy had been implemented. There are thus 1000 implementations of each sampling strategy, which were used to generate statistics showing the resulting distributions of measurements and the WFD classifications which would have been obtained. In particular, the means and $95 \%$ confidence limits on the means were calculated and are used in the following analysis. The $95 \%$ confidence limits were calculated as the 2.5 th and 97.5 th percentiles of the distribution of means generated by the 1000 trials - this is the percentile bootstrap confidence interval (Davison and Hinkley, 1997; Sect. 5.3), which will simply be referred to in this paper as the confidence interval (CI).

\section{Results and discussion}

Figures 2 to 5 show the means and $95 \%$ confidence intervals for four determinands $-\mathrm{P}$ species, dissolved oxygen, $\mathrm{pH}$ and 


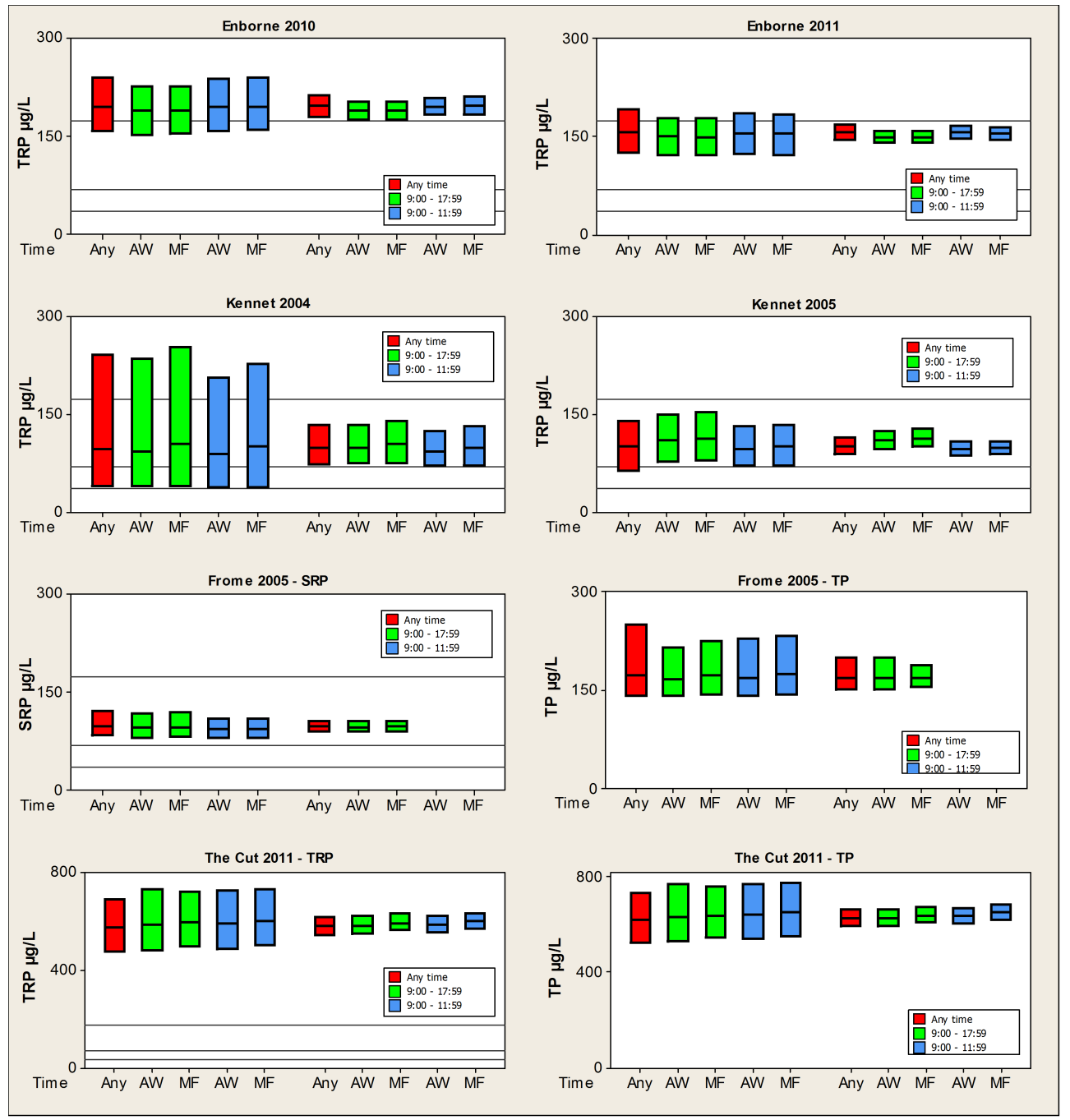

Figure 2. Means and $95 \%$ confidence intervals for phosphorus species generated by resampling from high-frequency data. First five columns: monthly sampling; remaining five: weekly sampling. Red bars - at any date or time; green - working hours (09:00-17:59) only; blue 09:00-11:59 only. AW - on any day of the week; MF - Monday to Friday only. Horizontal lines represent Water Framework Directive class boundaries where applicable, from the bottom: High/Good; Good/Moderate; Moderate/Poor. Note the different scale for The Cut. P species are defined in Sect. 2.2: TRP - total reactive phosphorus; SRP - soluble reactive phosphorus; TP - total phosphorus.

water temperature - given different sampling strategies. The five bars on the left of each graph represent monthly sampling; those on the right, weekly sampling. Within each of these the sampling strategies represent (from left to right) the ANY; AW9-18; MF9-18; AW9-12; and MF9-12 sampling strategies (see previous paragraph). The boundaries between different river quality classes in the UK implementation of the WFD are also shown where appropriate. The statistics plotted are those used in the UK for the WFD: means for $\mathrm{pH}$ and $\mathrm{P}$ species; the 10th percentile for dissolved oxygen; and the 98th percentile for water temperature.

\subsection{Monthly versus weekly sampling}

Though it is clear a priori that weekly sampling will give a more precise estimate than monthly sampling, Figs. 2 to 5 show that the magnitude of the effect varies between determinands and sites, and even between different years at the same site. The improvement in precision between monthly and weekly sampling is however generally considerable. For instance, the mean TRP in the River Kennet in 2004 for the MF9-18 sampling strategy (Fig. 2) was $103 \mu \mathrm{g} \mathrm{PL}{ }^{-1}$, with a $95 \%$ confidence interval (CI) of $38-251 \mu \mathrm{g} \mathrm{P} \mathrm{L}^{-1}$. For weekly sampling the corresponding CI was 74-138 $\mu \mathrm{g} \mathrm{PL} \mathrm{L}^{-1}$; mean, $102 \mu \mathrm{g} \mathrm{PL}^{-1}$. As can be seen in Fig. 2, the monthly TRP CI covers three WFD classes (poor, moderate and good, just missing high), whereas the weekly sampling CI is 


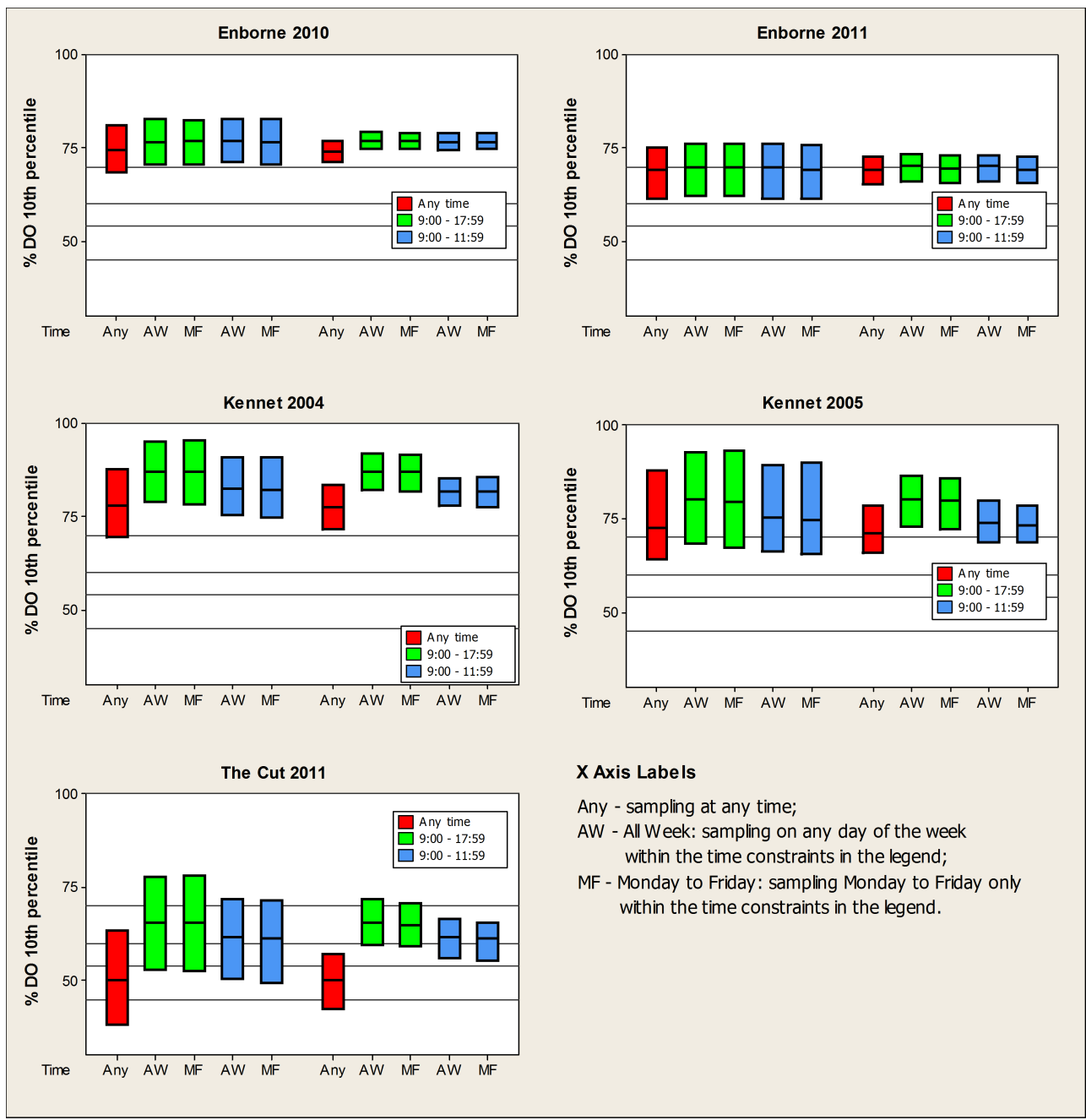

Figure 3. Mean 10th percentiles and $95 \%$ confidence intervals for dissolved oxygen generated by resampling from high-frequency data. First five columns: monthly sampling; remaining five: weekly sampling. Horizontal lines represent Water Framework Directive class boundaries - from the top: High/Good; Good/Moderate; Moderate/Poor; Poor/Bad.

contained entirely within the moderate class. Similarly, the 95\% CI for MF9-18 sampling of TRP on The Cut covers $247 \mu \mathrm{P} \mathrm{L}^{-1}$ (480-727), whereas the corresponding $95 \% \mathrm{CI}$ for weekly sampling is only $70 \mu \mathrm{P} \mathrm{L}^{-1}$ (546-616), though all samples are in the "poor" WFD class. The width of the weekly sampled confidence intervals was about $33 \%$ that of the monthly for $\mathrm{P}$ species and $\mathrm{pH}$ (Figs. 2 and 4), about $50 \%$ for dissolved oxygen (Fig. 3) and about $67 \%$ for temperature (Fig. 5). Whether the improvement of precision of weekly sampling makes any difference to the possible range of WFD classes depends on the closeness of the range of concentrations to the class boundaries. For instance, monthly sampling of temperature is less precise than weekly (Fig. 5), but this makes no difference to the WFD classification except on The Cut, whereas for P species (Fig. 2) the difference is considerable.
Another way to evaluate the effect of sampling frequency on WFD classification is to calculate the probability that a water body will be allocated to a given class in any one year. This is shown for dissolved oxygen (DO) on The Cut in Fig. 6, and TRP on the Kennet in Fig. 7. Monthly sampling at any time could result in The Cut being allocated to any of the five WFD classes in any one year due to random sampling effects (with a $0.3 \%$ chance of "high" just visible on the diagram). The probability of any one year being allocated to the correct class for this sampling strategy, which was "poor" according to the high-frequency data, was just $47 \%$. In contrast, weekly sampling under the same conditions allocated The Cut to three classes, with a $78 \%$ chance of "poor". These results have implications for detecting trends in the data. For instance, using the most common sampling strategy (MF9-18), the probability of the WFD class being correctly assigned to "good" is $52 \%$ for monthly 

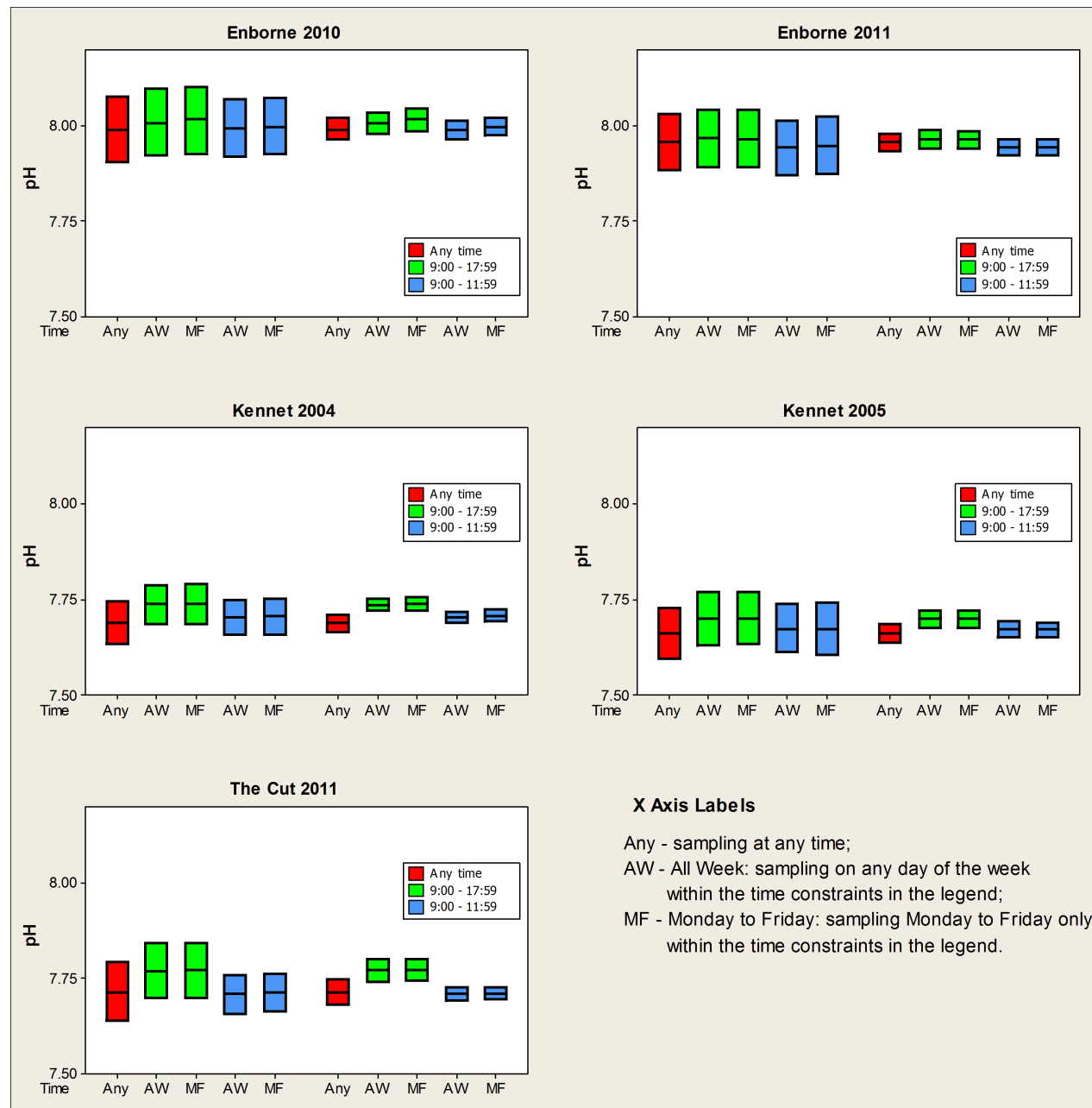

Figure 4. Means and $95 \%$ confidence intervals for $\mathrm{pH}$ generated by resampling from high-frequency data. First five columns: monthly sampling; remaining five: weekly sampling. The WFD class is uniformly "high" $(\mathrm{pH}>6.60)$.

sampling and $89 \%$ for weekly sampling (Fig. 6). Assuming DO concentrations stayed the same for 5 years, the probability of the classification being correct in every year is only $4 \%$ $\left(0.52^{5}\right)$ with monthly sampling, whereas it is $54 \%\left(0.89^{5}\right)$ with weekly sampling. The potential for generating spurious "trends" in the WFD classification due to purely random sampling effects is obvious, if the sampling frequency is not great enough. For TRP on the Kennet (Fig. 7), weekly sampling always produces the correct classification of "good", whereas with monthly sampling the classification is correct only $65-75 \%$ of the time. Proportions of other classifications are "moderate", 16-20\%; "poor", 5-11\%; and "high", $0-2 \%$, indicating the considerable uncertainty and wide range of possible classifications if the sampling frequency is not high enough. These considerations apply when the confidence intervals of the mean re-sampled concentrations crosses one or more WFD class boundaries - inspection of Figs. 2-5 shows where this occurs. For some cases, e.g. pH (Fig. 4), class boundaries are not crossed and any sampling strategy always gives the same classification.

For $\mathrm{P}$ species, DO, and $\mathrm{pH}$, the means of the monthly and weekly sampled average values are essentially the same (Figs. 2-5). They are also close to the true means calculated from all the high-frequency observed data - normally within $1 \%$ of the true mean value, with weekly sampling a little more precise. This shows that sampling introduces no systematic bias, and the means shown in Figs. 2 to 5 represent the observed means. It does not follow from this that monthly and weekly sampling would generally give the same mean in a given year - only that the mean would be the same if it was possible to continue the sampling for long enough, effectively 1000 years in this case. For the 98th percentile water temperatures, however, the yearly means of monthly samples are clearly lower than the weekly means (Fig. 5), and sampling frequency does introduce a systematic bias. Table 2 shows the true and sampled temperatures for each river 


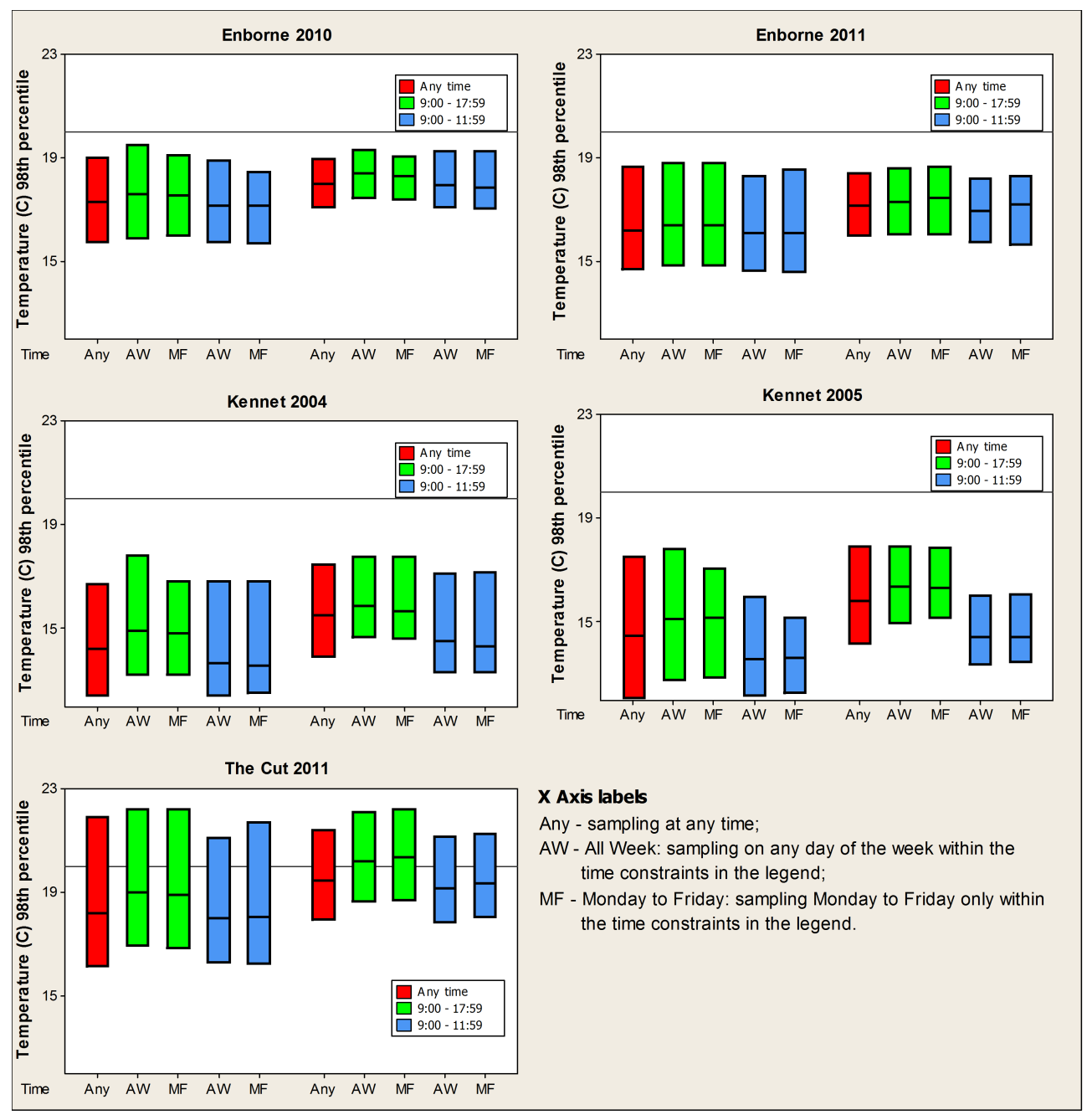

Figure 5. Mean 98th percentiles and $95 \%$ confidence intervals for water temperature generated by resampling from high-frequency data. First five columns: monthly sampling; remaining five: weekly sampling. Horizontal line represents the Water Framework Directive class boundary between "high" $\left(<20^{\circ} \mathrm{C}\right)$ and "good".

and sampling strategy, "true" being defined as the temperature calculated from all the measured data for the particular frequency, strategy and river. Table 2 shows that monthly sampling is underestimating water temperatures by about $1{ }^{\circ} \mathrm{C}$, sometimes more, whereas weekly sampling overestimates less consistently, by about $0.1^{\circ} \mathrm{C}$. These differences arise from the methods used to interpolate the 98 th percentile temperature. When there are not many measurements (as in the monthly samples here), a systematic bias is likely as well as wide confidence intervals. The problems involved in the estimation of percentiles used as water quality standards are extensively discussed by Ellis and Lacey (1980), who note that the confidence limits are likely to be very wide for high (or low) percentiles and depend markedly on the underlying distributions of the measured values. The adoption of a 98th percentile as a standard was probably intended to apply to continuously measured temperature data where the large number of data points reduces both random error and systematic bias in estimation of the percentile. Use of a high percentile as a standard with spot measurements, which are typically fewer in number, needs to be more critically evaluated.

\subsection{Diurnal sampling precision}

One aim of this paper is to investigate whether restricting the times at which samples are taken would improve the precision of the estimates for the chemical variables. This can be measured by comparing the height of each bar in Figs. 2-5 with the bar corresponding to unrestricted sampling ("ANY"). Table 3 shows a quantitative measure of this, i.e. $95 \% \mathrm{CI}_{(\mathrm{s})} / 95 \% \mathrm{CI}_{(\text {Any) }}$ expressed as a percentage, where $95 \% \mathrm{CI}_{(\mathrm{s})}$ is the $95 \%$ confidence interval for a particular strategy and $95 \% \mathrm{CI}_{(\mathrm{Any})}$ is the $95 \% \mathrm{CI}$ for sampling at any time. Overall, restricting the sampling time improves the 
Table 2. Sampled and true 98th percentile temperatures for the rivers and sampling strategies.

\begin{tabular}{|c|c|c|c|c|c|c|c|c|}
\hline Temp. & Frequency & Strategy & En10 & En11 & Ken04 & Ken05 & Cut11 & Mean \\
\hline True & Monthly & ANY & 18.01 & 17.05 & 15.20 & 15.80 & 19.08 & 17.03 \\
\hline Sampled & Monthly & ANY & 17.28 & 16.19 & 14.19 & 14.51 & 18.17 & 16.07 \\
\hline Difference & Monthly & ANY & -0.73 & -0.86 & -1.01 & -1.29 & -0.91 & -0.96 \\
\hline True & Monthly & AW9-18 & 18.40 & 17.16 & 15.70 & 16.32 & 20.01 & 17.52 \\
\hline Sampled & Monthly & AW9-18 & 17.59 & 16.38 & 14.90 & 15.14 & 18.97 & 16.59 \\
\hline Difference & Monthly & AW9-18 & -0.81 & -0.78 & -0.80 & -1.18 & -1.04 & -0.92 \\
\hline True & Monthly & MF9-18 & 18.36 & 17.74 & 15.50 & 16.30 & 20.01 & 17.58 \\
\hline Sampled & Monthly & MF9-18 & 17.53 & 16.38 & 14.80 & 15.21 & 18.89 & 16.56 \\
\hline Difference & Monthly & MF9-18 & -0.83 & -1.36 & -0.70 & -1.09 & -1.12 & -1.02 \\
\hline True & Monthly & AW9-12 & 17.88 & 16.86 & 14.00 & 14.40 & 18.81 & 16.39 \\
\hline Sampled & Monthly & AW9-12 & 17.17 & 16.08 & 13.67 & 13.60 & 17.98 & 15.70 \\
\hline Difference & Monthly & AW9-12 & -0.71 & -0.78 & -0.33 & -0.80 & -0.83 & -0.69 \\
\hline True & Monthly & MF9-12 & 17.79 & 17.38 & 13.90 & 14.40 & 18.98 & 16.49 \\
\hline Sampled & Monthly & MF9-12 & 17.14 & 16.12 & 13.54 & 13.65 & 18.04 & 15.70 \\
\hline Difference & Monthly & MF9-12 & -0.65 & -1.26 & -0.36 & -0.75 & -0.94 & -0.79 \\
\hline True & Weekly & ANY & 18.01 & 17.05 & 15.20 & 15.80 & 19.08 & 17.03 \\
\hline Sampled & Weekly & ANY & 18.01 & 17.15 & 15.24 & 15.82 & 19.42 & 17.13 \\
\hline Difference & Weekly & ANY & 0.00 & 0.10 & 0.04 & 0.02 & 0.34 & 0.10 \\
\hline True & Weekly & AW9-18 & 18.40 & 17.16 & 15.70 & 16.32 & 20.01 & 17.52 \\
\hline Sampled & Weekly & AW9-18 & 18.39 & 17.29 & 15.84 & 16.40 & 20.16 & 17.62 \\
\hline Difference & Weekly & AW9-18 & -0.01 & 0.13 & 0.14 & 0.08 & 0.15 & 0.10 \\
\hline True & Weekly & MF9-18 & 18.36 & 17.74 & 15.50 & 16.30 & 20.01 & 17.58 \\
\hline Sampled & Weekly & MF9-18 & 18.29 & 17.43 & 15.63 & 16.31 & 20.30 & 17.59 \\
\hline Difference & Weekly & MF9-18 & -0.07 & -0.31 & 0.13 & 0.01 & 0.29 & 0.01 \\
\hline True & Weekly & AW9-12 & 17.88 & 16.86 & 14.00 & 14.40 & 18.81 & 16.39 \\
\hline Sampled & Weekly & AW9-12 & 17.94 & 16.95 & 14.49 & 14.41 & 19.13 & 16.58 \\
\hline Difference & Weekly & AW9-12 & 0.06 & 0.09 & 0.49 & 0.01 & 0.32 & 0.19 \\
\hline True & Weekly & MF9-12 & 17.79 & 17.38 & 13.90 & 14.40 & 18.98 & 16.49 \\
\hline Sampled & Weekly & MF9-12 & 17.85 & 17.19 & 14.30 & 14.44 & 19.32 & 16.62 \\
\hline Difference & Weekly & MF9-12 & 0.06 & -0.19 & 0.40 & 0.04 & 0.34 & 0.13 \\
\hline
\end{tabular}

precision of the estimates in $71 \%$ of cases - those where it does not do so are highlighted in the table. The most consistent improvements in precision are obtained using the $3 \mathrm{~h}$ sampling strategies (AW9-12 and MF9-12) for TRP, DO and $\mathrm{pH}$ with weekly sampling. Monthly sampling shows a similar pattern but is less consistent. In general, the $3 \mathrm{~h}$ strategies improve the precision more than the full working hours strategies (AW9-18 and MF9-18) - the average CI is $88 \%$ of unrestricted for the 9-12 strategies versus $95 \%$ for the
9-18 strategies. There is no overall difference between the precision of sampling on the AW versus the MF strategies (both $91 \%$ of unrestricted). There are differences in response between the rivers, and between the same river in different years, and between weekly and monthly sampling. In spite of these inconsistencies, however, it seems that restricting the sampling time to a $3 \mathrm{~h}$ window would in general give a worthwhile improvement in precision of the estimates of the 

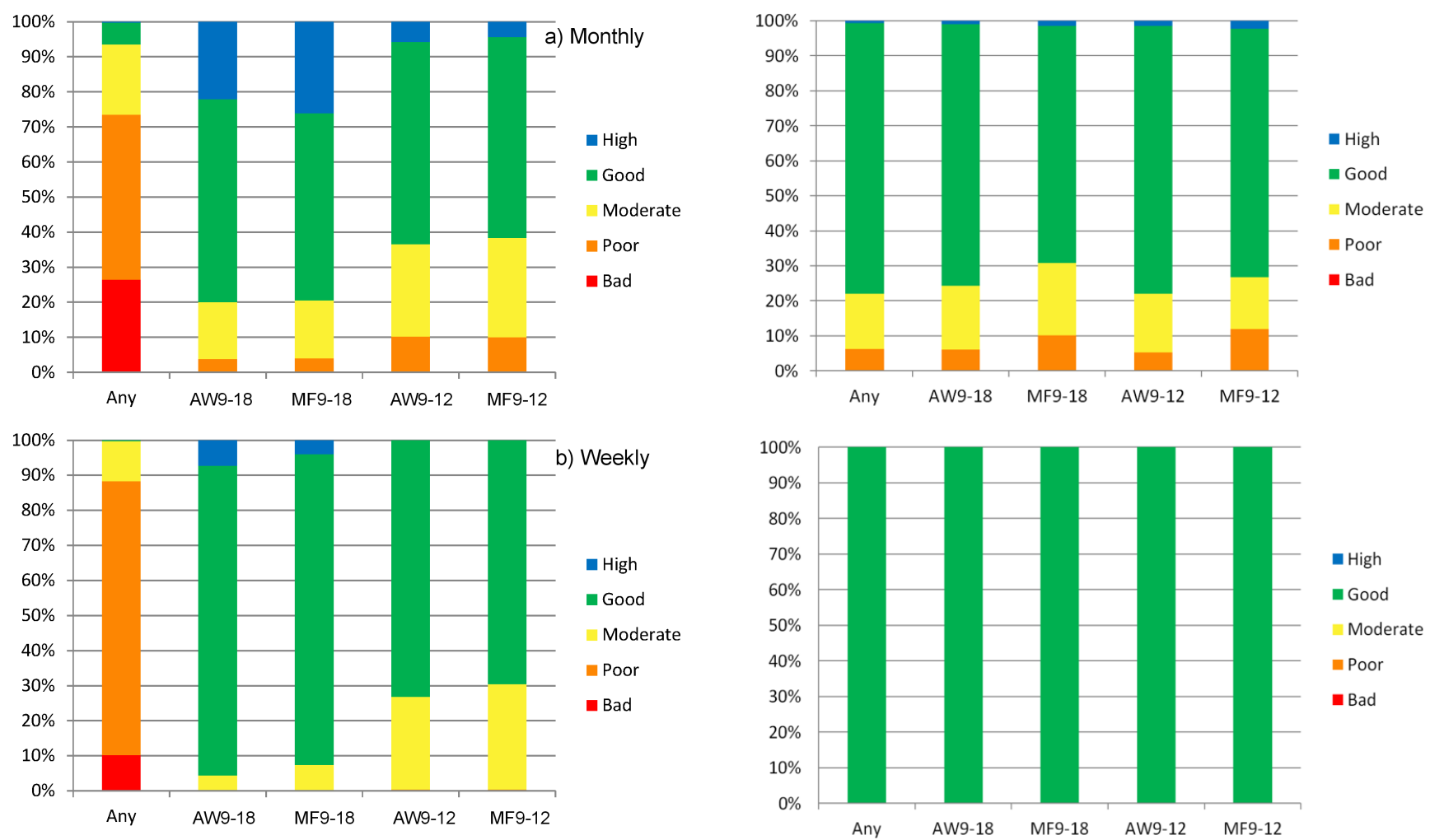

Figure 6. The probability that sampling dissolved oxygen on The Cut for 1 year would put the river into a given WFD class, (a) monthly sampling, and (b) weekly sampling. Strategy labels: Any - at any time; AW9-18 - all week, working hours (09:00 to 17:59); MF9-18 - Monday to Friday, working hours; AW9-12 - all week, 09:00 to 11:59; MF9-12 - Monday to Friday, 09:00 to 11:59.

four chemical variables, and thus a more accurate estimate of the WFD class.

\subsection{Different sampling strategies lead to different estimates of variables}

It is clear from Figs. 2 to 5 that different sampling strategies give different estimates for the variables being considered. Apart from the differences in water temperature between monthly and weekly sampling referred to in Sect. 3.1, these are largely due to diel variations in processes affecting the variables. It is well known that DO has a strong diel variation due to the balance between photosynthesis and respiration, with low DO concentrations at night when there is no photosynthesis and high concentrations during the day when photosynthesis is active. This explains the patterns seen in Fig. 3, when the AW/MF9-18 strategies have higher DO concentrations than the average for the entire $24 \mathrm{~h}$ (ANY), and the AW/MF9-12 strategies are intermediate (as DO concentrations are generally higher in the afternoon). The patterns are most pronounced on The Cut, which has a very strong diel DO cycle (Wade et al., 2012; Halliday et al., 2015), and least on the Enborne, where heavy riparian shading due to decid-

Figure 7. The probability that sampling TRP on the River Kennet for 1 year would put the river into a given WFD class, (a) monthly sampling, and (b) weekly sampling. Strategy labels: Any - at any time; AW9-18, all week, working hours (09:00 to 17:59); MF918, Monday to Friday, working hours; AW9-12, all week, 09:00 to 11:59; and MF9-12, Monday to Friday, 09:00 to 11:59.

uous trees restricts a strong diel DO cycle to the early spring (Halliday et al., 2014). The same cycle can be seen in the $\mathrm{pH}$ values (Fig. 4), where higher $\mathrm{pH}$ in the AW/MF9-18 samples is due to lower carbonic acid concentrations during the day because of photosynthetic uptake of carbon. Likewise, the prevalence of high water temperatures is lower in the morning than for the whole day, or even the full $24 \mathrm{~h}$ (Fig. 5). Phosphorus species have a less obvious pattern (Fig. 2), though there is a suggestion that MF values are slightly higher than AW values, reflecting a different outflow pattern from sewage treatment works between weekday and weekend (see Halliday et al., 2014).

These results raise the question of which sampling strategy generates the best concentration estimates for use in WFD classifications. The differences between strategies are greatest with dissolved oxygen, and can substantially affect the WFD classification. To take the most extreme example, The Cut has a classification of "poor" if sampled at any time of day (ANY), "good" if sampled at any time during working hours, and "good" but with less certainty if sampled from 09:00 to 11:59. It could be argued that "poor" is the correct classification, since organisms are exposed to conditions 
Table 3. $95 \%$ confidence intervals for each strategy as a percentage of the $95 \%$ CI for sampling at any time.

\begin{tabular}{llrrrrr}
\hline & River & En10 & En11 & Ken04 & Ken05 & Cut11 \\
\hline (a) TRP & & & & & & \\
\hline Monthly & AW9-18 & 91 & 84 & 97 & 97 & $\mathbf{1 1 6}$ \\
Monthly & MF9-18 & 87 & 83 & $\mathbf{1 0 6}$ & 99 & $\mathbf{1 0 5}$ \\
Monthly & AW9-12 & 97 & 93 & 83 & 82 & $\mathbf{1 1 2}$ \\
Monthly & MF9-12 & 97 & 94 & 94 & 84 & $\mathbf{1 0 7}$ \\
Weekly & AW9-18 & 79 & 86 & 97 & $\mathbf{1 0 7}$ & 96 \\
Weekly & MF9-18 & 79 & 78 & $\mathbf{1 0 7}$ & $\mathbf{1 0 7}$ & 95 \\
Weekly & AW9-12 & 80 & 89 & 89 & 86 & 91 \\
Weekly & MF9-12 & 83 & 82 & 100 & 82 & 87
\end{tabular}

(b) Dissolved oxygen

\begin{tabular}{llrrrrr}
\hline Monthly & AW9-18 & 93 & $\mathbf{1 0 2}$ & 89 & $\mathbf{1 0 2}$ & 100 \\
Monthly & MF9-18 & 92 & $\mathbf{1 0 2}$ & 94 & $\mathbf{1 0 8}$ & $\mathbf{1 0 2}$ \\
Monthly & AW9-12 & 91 & $\mathbf{1 0 6}$ & 85 & 97 & 85 \\
Monthly & MF9-12 & 93 & $\mathbf{1 0 4}$ & 87 & $\mathbf{1 0 2}$ & 88 \\
Weekly & AW9-18 & 81 & 100 & 83 & $\mathbf{1 0 7}$ & 84 \\
Weekly & MF9-18 & 72 & $\mathbf{1 0 1}$ & 84 & $\mathbf{1 0 9}$ & 78 \\
Weekly & AW9-12 & 82 & 98 & 63 & 88 & 70 \\
Weekly & MF9-12 & 77 & 99 & 69 & 79 & 71 \\
\hline (c) pH & & & & & & \\
\hline Monthly & AW9-18 & $\mathbf{1 0 5}$ & $\mathbf{1 0 3}$ & 89 & $\mathbf{1 0 5}$ & 94 \\
Monthly & MF9-18 & $\mathbf{1 0 4}$ & $\mathbf{1 0 2}$ & 93 & $\mathbf{1 0 4}$ & 95 \\
Monthly & AW9-12 & 88 & 99 & 82 & 95 & 67 \\
Monthly & MF9-12 & 87 & $\mathbf{1 0 4}$ & 87 & $\mathbf{1 0 2}$ & 63 \\
Weekly & AW9-18 & 98 & $\mathbf{1 0 7}$ & 80 & 90 & 90 \\
Weekly & MF9-18 & $\mathbf{1 0 2}$ & $\mathbf{1 0 1}$ & 86 & 90 & 86 \\
Weekly & AW9-12 & 86 & 94 & 70 & 82 & 54 \\
Weekly & MF9-12 & 81 & 95 & 73 & 77 & 50
\end{tabular}

(d) Temperature

\begin{tabular}{llrrrrr}
\hline Monthly & AW9-18 & $\mathbf{1 0 9}$ & $\mathbf{1 0 1}$ & $\mathbf{1 0 7}$ & 93 & 91 \\
Monthly & MF9-18 & 95 & $\mathbf{1 0 1}$ & 84 & 78 & 93 \\
Monthly & AW9-12 & 96 & 93 & $\mathbf{1 0 2}$ & 70 & 84 \\
Monthly & MF9-12 & 85 & $\mathbf{1 0 1}$ & 100 & 54 & 94 \\
Weekly & AW9-18 & 98 & $\mathbf{1 0 7}$ & 87 & 78 & 100 \\
Weekly & MF9-18 & 88 & $\mathbf{1 1 0}$ & 88 & 71 & $\mathbf{1 0 2}$ \\
Weekly & AW9-12 & $\mathbf{1 1 5}$ & $\mathbf{1 0 4}$ & $\mathbf{1 0 8}$ & 70 & 95 \\
Weekly & MF9-12 & $\mathbf{1 1 7}$ & $\mathbf{1 1 0}$ & $\mathbf{1 0 8}$ & 69 & 92 \\
\hline
\end{tabular}

Abbreviations for the rivers are, respectively (Enborne, 2010, 2011; Kennet, 2004, 2005), The Cut 2011; AW9-18, all week, working hours (09:00 to 17:59); MF9-18, Monday to Friday, working hours; AW9-12, all week, 09:00 to 11:59; and MF9-12, Monday to Friday, 09:00 to 11:59. Percentages greater than 100 are highlighted in bold font.

throughout the $24 \mathrm{~h}$ period, including low DO concentrations during the night. Conversely it could be argued that since the boundaries between the WFD classes are derived in the UK from statistical associations between chemical parameters and biological quality based on sampling at conventional times, i.e. during working hours, then the correct classification is "good". Whether "good" is a reasonable representation may depend on the diel dynamics of DO at the particular site. The Cut is a productive stream with both high photosynthesis and respiration rates - DO concentrations can fall to as little as $27 \%$ at night (Wade et al., 2012; Halliday et al., 2015). The Enborne in 2011 would also have been classi- fied as "good", but the magnitude of diel fluctuations is much smaller, with night-time DO concentrations no lower than $60 \%$ (Halliday et al., 2014). Clearly The Cut is much more at risk of deleterious effects due to anoxia than the Enborne, but the daytime sampling regime does not register this difference very strongly (Fig. 3). If the issue is low night-time DO concentrations, and the measurements are available because the site is being continuously monitored, then it would seem more logical to use measurements made at night as the standard. The Cut might however be seen as an extreme case given its high STW load, and comparing the working day and anytime means and CIs in Fig. 3 shows that working day sampling is a better representation of the full range of DO concentrations on the Enborne than The Cut, with the Kennet intermediate. Based on this sample of three rivers, it may be that daytime sampling for DO is not a good measure of risk for rivers with high respiration rates due to organic loading and/or high rates of primary production. This would need further investigation on more sites. What is not satisfactory, however, is that it is possible to obtain such widely differing WFD classifications because the sampling time is not defined. Defining a sampling time as part of the assessment procedure would be a straightforward process and reduce some of the uncertainty being discussed here, as previously suggested for The Cut by Halliday et al. (2015).

\subsection{Differences between years}

The Kennet and Enborne were both assessed for 2 consecutive years, and it is therefore possible to obtain an indication of the extent to which chemical concentrations and WFD class assignments are stable with time. River $\mathrm{pH}$ was essentially the same between years (Fig. 4), but the other determinands show differences. TRP concentrations fell between 2010 and 2011 on the Enborne (Fig. 2), increasing the WFD class from "poor" to "moderate". If non-overlapping confidence intervals are taken as a measure of a significant difference, this is a significant improvement detectable with weekly sampling, but not with monthly sampling. This is the only significant difference between years evident in the data. DO, in contrast, declined on the Enborne between the same years, and the mean WFD class fell from "high" to "good". On the Kennet, the mean TRP stayed much the same between years, but TRP had much wider confidence intervals in 2004 than in 2005, due to some especially high values. DO was lower on the Kennet in 2005 than in 2004, though the WFD classification did not change. The differences between years are likely to be due to hydrological differences rather than any change in management. On the Kennet, flows in 2004 were close to the long-term average, whereas 2005 was a dry year, with flows only $62 \%$ of the average (UKNRFA, 2014), leading to a higher volume-specific rate of oxygen consumption, which depresses the 10th percentile value. On the Enborne, 2010 was a wetter year than 2011, with high and variable flows at the beginning of the period, explaining 
the greater variation in most concentrations in 2010 observable in Figs. 2-5. In general, the range in concentrations is determined by individual flow events which are not apparent in annually aggregated statistics, but this study illustrates that such differences do occur and will add to the variation observed.

\section{Wider discussion}

This study shows that for these four rivers, the WFD class cannot be assigned with $95 \%$ confidence for a number of variables and sampling strategies. Taking the strategy most commonly used in practice, MF9-18, the WFD class cannot be assigned for monthly sampling of phosphorus on the Enborne in 2010 and 2011 and the Kennet in 2004; dissolved oxygen on the Enborne in 2011, the Kennet in 2005 and The Cut in 2011; and water temperature on The Cut in 2011. For weekly sampling, the WFD class cannot be assigned for dissolved oxygen on the Enborne in 2011 and The Cut in 2011, and temperature on The Cut in 2011. Clearly, weekly sampling generates less ambiguity, and this matches the conclusions of Johnes (2007) that monthly sampling gave highly uncertain load estimates for a variety of British rivers, including the Enborne. In contrast, the WFD class can be assigned unambiguously for $\mathrm{pH}$ on all rivers and temperature in most (all "high") and phosphorus on The Cut ("poor"), whatever the sampling strategy. Where the sample mean is close to a class boundary (as for dissolved oxygen on the Enborne 2010), then consistent assignment to a single class is unlikely, but this should not be a major issue as long as the potential size of the confidence intervals is realised when drawing conclusions. Of most concern are situations where the confidence interval crosses several classes, as with dissolved oxygen on The Cut, which can be assigned to four WFD classes with $95 \%$ confidence given monthly sampling, as opposed to two or three classes with weekly sampling. It seems clear that if the aim is to identify WFD classes it would be better to spend limited resources on monitoring dissolved oxygen than $\mathrm{pH}$ in these rivers. This sort of judgement should be made in the light of technical knowledge and considering the objectives of the monitoring programme. For instance, all these rivers are fed by well-buffered calcareous groundwater and monitoring shows the $\mathrm{pH}$ to be well above the high/good boundary. A change of WFD status for $\mathrm{pH}$ is thus unlikely and occasional monitoring (e.g. twice a year) would suffice. The same considerations might apply to $\mathrm{P}$ concentrations on The Cut, which are unlikely to drop below "poor" in view of the high P load from sewage treatment works, except that here the WFD objectives specify that P concentrations should be reduced in an attempt to improve the classification. Hence more frequent monitoring is justified even though the classification is likely to remain "poor" for the foreseeable future, and it becomes relevant that the $95 \%$ confidence interval for monthly sampling is around $250 \mu \mathrm{g} \mathrm{PL}^{-1}$ as opposed to $70 \mu \mathrm{g} \mathrm{P} \mathrm{L}^{-1}$ for weekly sampling. For detection of likely trends, weekly sampling will be required. This differentiated approach to monitoring is suggested in the WFD. In practice, sampling effort may not be affected much if more frequent samples have to be taken from the same site in any case, but analytical effort may be reduced given that different determinands are analysed using different equipment.

The results show that there is little difference between sampling Monday to Friday or during the whole week. Differences can be seen in Figs. 2-5, but they are generally small in magnitude and not consistent in direction. Phosphorus is the determinand for which differences might be most likely, as the pattern of sewage treatment works output differs somewhat between weekdays and weekends (e.g. Halliday et al., 2014), but this is not apparent in Fig. 2. On the other hand, restricting sampling to the $3 \mathrm{~h}$ period between 09:00 and 11:59 leads to an improvement in precision for TRP, dissolved oxygen and $\mathrm{pH}$, especially with weekly sampling (Table 3 ). The improvement is modest, amounting to a narrowing of the $95 \%$ confidence interval by about $13 \%$ for P, $20 \%$ for dissolved oxygen and $25 \%$ for $\mathrm{pH}$, for weekly samples, but it is consistent. For monthly samples the corresponding figures are 6,6 and $12 \%$ respectively, and the changes are not completely consistent in direction. For 98th percentile water temperature, there is no improvement in precision from restricting sampling times. The biggest improvements are shown by the determinands with the strongest diel variation $(\mathrm{pH}$ and dissolved oxygen), but are apparent for $\mathrm{P}$ as well. These improvements in precision seem worthwhile, so restricting the sampling time to a $3 \mathrm{~h}$ window seems a useful strategy, as it would be easy and cheap to implement.

In the case of the 98th percentile water temperature, monthly sampling not only gives wider confidence intervals than weekly sampling, but also biases the mean temperature estimates downwards by 0.7 to $1^{\circ} \mathrm{C}$ compared to the "true" value, depending on sampling strategy, while weekly sampling biases the means upwards by up to $0.2^{\circ} \mathrm{C}-$ a smaller change but still detectable given the precision of temperature measurement, and potentially significant when calculating limits. These biases arise from the method used to estimate percentiles. Estimation of a percentile with limited data requires either an assumption about, or assessment of, the distribution of values, or use of a distribution-free method which interpolates between values (see Ellis and Lacey, 1980). For monthly sampling (12 values) a 98th percentile cannot be interpolated, and is effectively assumed by the MATLAB function prctile to be the maximum sample value. For weekly sampling ( 52 values) the function interpolates between the two highest values - the bias introduced by this will depend on the behaviour of the extreme end of the distribution. As Ellis and Lacey (1980) state in a similar context, "even if the correct form of the distribution was known without doubt, the uncertainty in the estimate would render it virtually useless", and that calculating confidence limits for percentiles "is of limited value except in emphasizing the statistical haz- 
ards in this area". The conclusion for estimating the WFD limits is that the 98th percentile criterion should only be used where there are sufficient values to calculate a percentile, and cannot be done with spot sampled values at frequencies of weekly or greater.

One of the implications of the results in this paper is that the precision of sampling needs to be taken into account when designing mitigation strategies or other management interventions. For instance, managers should be discouraged from basing mitigation plans on non-compliance of one location in one year, in circumstances when the non-compliance could simply be due to sampling error. This will require a critical case-by-case look at each location and sampling strategy.

This study has also shown the need to define more precisely what a sample taken for WFD monitoring is meant to represent. Different WFD classifications can be obtained by regular sampling at different times of day, especially for variables with a strong diel variation, such as dissolved oxygen. This is surely an unsatisfactory situation, and it would be better to define a relatively narrow sampling time range to standardise this. There also needs to be some debate about whether a daytime sample for dissolved oxygen adequately represents the risk of anoxia occurring in all types of river, given the variety of behaviour exhibited by the Enborne and The Cut. Similar considerations apply to seasonal sampling, though are not covered in this paper. For instance, Rozemeijer et al. (2014) criticised the use of summer-only sampling for assessing nutrient losses from agriculture to surface water and groundwater.

This study is based on an illustrative but restricted sample of four rivers, and so must be applied with caution elsewhere. For instance, in the international context, these rivers are rather small (Table 1), though typical of rivers to which the WFD is applied in the UK. The conclusions may not be appropriate for much larger rivers - for instance, Liu et al. (2014) used an objective method to optimise sampling frequencies on the Xiangjiang River in China, concluding that adequate characterisation could be obtained by sampling at intervals varying between every 2 months and every 6 months. The Xiangiiang River, however, is a major tributary of the Yangtze, draining an area of $85000 \mathrm{~km}^{2}$, and sampling less frequently than once a month may be appropriate here as larger rivers will tend to have slower responses. Naddeo et al. (2013) suggested that for some rivers in southern Italy, of about the size of the Frome in this study or slightly larger, sampling frequencies could be reduced in some cases to less than once a month without affecting the WFD classification. However, neither of these studies considered sampling frequencies greater than monthly, assuming implicitly that monthly sampling gives the "correct" value. As shown in the present paper for these English rivers, this is not necessarily the case: a conclusion also supported in the context of load estimation by the work of Johnes (2007). The other relevant characteristic of the four rivers in the present study is their high baseflow index. This will reduce the temporal variability of most variables and hence increase sampling precision for a given sampling frequency. If the present methodology was applied to flashier rivers such as those studied by Cassidy and Jordan (2011), the confidence limits observed would probably be even wider.

\section{Conclusions}

Overall, a more critical attitude needs to be taken towards water sampling in support of the WFD in rivers such as these. For many parameters, routine monthly sampling is unlikely to be able to assign a classification accurately or to detect trends unless they are very large. However, for some parameters, such as $\mathrm{pH}$ in this case, monthly sampling is unnecessarily frequent and possibly a waste of resources. The wide confidence intervals observed even for weekly sampling in some cases imply that there is a real possibility of identifying deleterious "trends" which do not really exist and wasting resources trying to correct them, or alternatively failing to identify genuine water quality reductions and thus not taking the necessary improvement actions. This is particularly so given differences between years which are most probably driven by varying hydrological conditions. The precision and accuracy of measurements can be improved by specifying a sampling time interval, but a realistic assessment of the uncertainty attached to any given WFD classification seems essential before taking management action.

Acknowledgements. We would like to thank the Natural Environment Research Council for funding the monitoring of the rivers Frome and Kennet; the Engineering and Physical Sciences Research Council for funding the LIMPIDS project (EP/G019967/1) as part of which the Enborne and The Cut were monitored; and L. Palmer-Felgate, E. Gozzard, J. Newman, C. Roberts, L. Armstrong, S. Harman, and $\mathrm{H}$. Wickham for providing the field and laboratory support that produced the Kennet, Cut and Enborne data sets.

Edited by: B. Kronvang

\section{References}

Bowes, M. J., Leach, D. V., and House, W. A.: Seasonal nutrient dynamics in a chalk stream: the River Frome, Dorset, UK, Sci. Total Environ., 336, 225-241, doi:10.1016/j.scitotenv.2004.05.026, 2005.

Bowes, M. J., Smith, J. T., and Neal, C.: The value of high-resolution nutrient monitoring: A case study of the River Frome, Dorset, UK, J. Hydrol., 378, 82-96, doi:10.1016/j.jhydrol.2009.09.015, 2009.

Bowes, M. J., Smith, J. T., Neal, C., Leach, D. V., Scarlett, P. M., Wickham, H. D., Harman, S. A., Armstrong, L. K., DavyBowker, J., Haft, M., and Davies, C. E.: Changes in water quality 
of the River Frome (UK) from 1965 to 2009: Is phosphorus mitigation finally working?, Sci. Total Environ., 409, 3418-3430, doi:10.1016/j.scitotenv.2011.04.049, 2011.

Cassidy, R. and Jordan, P.: Limitations of instantaneous water quality sampling in surface-water catchments: comparison with nearcontinuous phosphorus time-series data, J. Hydrol., 405, 182193, 2011.

Davison, A. C. and Hinkley, D. V.: Bootstrap Methods and their Applications, Cambridge Series in Statistical and Probabilistic Mathematics, Cambridge University Press Cambridge, 1997.

Dixon, W. and Chiswell, B.: Review of aquatic monitoring program design, Water Res., 30, 1935-1948, doi:10.1016/00431354(96)00087-5, 1996.

Ellis, M. A. and Lacey, R. F.: Sampling; defining the task and planning the scheme, Water Pollut. Control., 79, 452-467, 1980.

EU: Directive 2000/60/EC of the European Parliament and of the Council of 23 October 2000 establishing a framework for Community action in the field of water policy, Official Journal of the European Communities, L327, 1-70, 2000.

EU: Common implementation strategy for the Water Framework Directive (2000/60/EC). Guidance document No. 19: guidance on surface water chemical monitoring under the Water Framework Directive, Luxembourg Technical Report 2009-025, 2009.

Halliday, S. J., Skeffington, R. A., Bowes, M. J., Gozzard, E., Newman, J. R., Loewenthal, M., Palmer-Felgate, E. J., Jarvie, H. P., and Wade, A. J.: The water quality of the River Enborne, UK: observations from high-frequency monitoring in a rural, lowland river system, Water, 6, 150-180, 2014.

Halliday, S. J., Skeffington, R. A., Wade, A. J., Bowes, M. J., Gozzard, E., Newman, J. R., Loewenthal, M., Palmer-Felgate, E. J., and Jarvie, H. P.: High-frequency water quality monitoring in an urban catchment: hydrochemical dynamics, primary production and implications for the Water Framework Directive, Hydrol. Process., doi:10.1002/hyp.10453, in press, 2015.

Horowitz, A. J.: A review of selected inorganic surface water quality-monitoring practices: are we really measuring what we think, and if so, are we doing it right?, Environ. Sci. Technol., 47, 2471-2486, 2013.

Hunt, D. T. E. and Wilson, A. L.: The chemical analysis of water: general principles and techniques, 2nd Edn., Royal Society of Chemistry, London, 1986.

Johnes, P.: Uncertainties in annual riverine phosphorus load estimation: impact of load estimation methodology, sampling frequency, baseflow index and catchment population density, J. Hydrol., 332, 241-258, 2007.
Kronvang, B. and Bruhn, A.: Choice of sampling strategy and estimation method for calculating nitrogen and phosphorus transport in small lowland streams, Hydrol. Process., 10, 1483-1501, 1996.

Liu, Y., Zheng, B., Wang, M., Xu, Y., and Qin, Y.: Optimization of sampling frequency for routine river water quality monitoring, Sci. China Chem., 57, 772-778, 2014.

MATLAB: available at: http://www.mathworks.co.uk/products/ matlab/, last access: 20 September 2014.

Murphy, J. and Riley, J.: A modified single solution method for the determination of phosphate in natural waters, Anal. Chim. Acta, 27, 31-36, 1962.

Naddeo, V., Scannapieco, D., Zarra, T., and Belgiorno, V.: River water quality assessment: Implementation of non-parametric tests for sampling frequency optimization, Land Use Pol., 30, 197205, 2013.

Palmer-Felgate, E. J., Jarvie, H. P., Williams, R. J., Mortimer, R. J. G., Loewenthal, M., and Neal, C.: Phosphorus dynamics and productivity in a sewage-impacted lowland chalk stream, J. Hydrol., 351, 87-97, doi:10.1016/j.jhydrol.2007.11.036, 2008.

Rozemeijer, J. C., Klein, J., Broers, H. P., van Tol-Leenders, T. P., and van der Grift, B.: Water quality status and trends in agriculture-dominated headwaters; a national monitoring network for assessing the effectiveness of national and European manure legislation in The Netherlands, Environ. Monitor. Assess., 186, 8981-8995, 2014.

Strobl, R. O. and Robillard, P. D.: Network design for water quality monitoring of surface freshwaters: A review, J. Environ. Manage., 87, 639-648, doi:10.1016/j.jenvman.2007.03.001, 2008.

UK National River Flow Archive: available at: http://www.ceh.ac. uk/data/nrfa/index.html, last access: 14 September 2014.

Wade, A. J., Palmer-Felgate, E. J., Halliday, S. J., Skeffington, R. A., Loewenthal, M., Jarvie, H. P., Bowes, M. J., Greenway, G. M., Haswell, S. J., Bell, I. M., Joly, E., Fallatah, A., Neal, C., Williams, R. J., Gozzard, E., and Newman, J. R.: Hydrochemical processes in lowland rivers: insights from in situ, highresolution monitoring, Hydrol. Earth Syst. Sci., 16, 4323-4342, doi:10.5194/hess-16-4323-2012, 2012. 